\title{
Intravitreal gas injection for the treatment of diabetic macular edema
}

This article was published in the following Dove Press journal:

Clinical Ophthalmology

25 October 20II

Number of times this article has been viewed

\section{Dominic McHugh \\ Bhaskar Gupta \\ Manzar Saeed}

King's College Hospital, Denmark Hill, London, England, UK
Correspondence: Bhaskar Gupta King's College Hospital, Denmark Hill, London SE5 9RS, England, UK

Tel +442032994548

Fax +44 2032993738

Email gupta_bhaskar@yahoo.com
Purpose: This study investigates the efficacy of an intravitreal gas injection in inducing a posterior vitreous detachment (PVD) in patients with clinically significant diabetic macular edema refractory to laser therapy.

Methods: A local ethics committee-approved technique of an intravitreal injection of pure perfluoropropane gas $\left(\mathrm{C}_{3} \mathrm{~F}_{8}\right)$ was performed for all participants. After a period of prone positioning, the patients underwent regular and detailed clinical review.

Main outcome measures: The induction of a PVD, change in macular thickness, change in visual acuity.

Results: A PVD was induced in all five eyes with subsequent signs of reduction in macular thickness and resolution of exudates. Mean visual improvement was 11 ETDRS (Early Treatment Diabetic Retinopathy Study) letters (range 4-21). Apart from a transient vitreous hemorrhage in one eye, there were no significant treatment-related complications.

Conclusion: The induction of a PVD by pneumatic retinopexy appears to have a significant influence on diabetic macular edema in eyes which have not successfully responded to macular laser therapy. A randomized clinical trial is justified on the basis of the initial promising data.

Keywords: optical coherence tomography, OCT, posterior vitreous detachment, perfluoropropane

\section{Introduction}

Diabetic retinopathy is the commonest cause of blindness in patients of working age in developed countries, principally due to the complications of neovascularization, or to maculopathy (focal or diffuse macular edema). ${ }^{1,2}$ Although considerable progress has been made in reducing the incidence of blindness through improved medical control, screening, and timely laser therapy, ${ }^{3-6}$ many patients with maculopathy are either relatively resistant to photocoagulation, or develop recurrent edema, with consequent visual deterioration despite undergoing repeat laser therapy. ${ }^{7}$ Reported outcomes from vitreoretinal surgery for macular edema have been relatively disappointing, with the risk of sight-threatening side effects arising from such a complex procedure. ${ }^{8,9}$ Intravitreal steroids and anti-vascular endothelial growth factor (anti-VEGF) preparations are increasingly employed, but there is also a recognized morbidity and a requirement for repeated injections. ${ }^{10,11}$

It is likely that the pathogenesis of diabetic macular edema is due to a complex interaction of a number of factors, and these include vitreoretinal relationships at the macula. Specifically, it seems that an attached vitreous may tend to sustain or exacerbate edema, while conversely a posterior vitreous detachment (PVD) may ameliorate 
existing retinopathy. ${ }^{12,13}$ These observations provided the rationale for the current study, whereby a technique of intravitreal gas injection was employed to evaluate its effect on diabetic macular edema through the induction of a PVD.

\section{Methods}

The study design was of an open label, nonrandomized, prospective trial. A detailed protocol was submitted to and agreed by the local ethics committee. All patients provided fully informed consent before enrolment in the study.

Inclusion criteria were:

- Medically diagnosed diabetes (type I or II);

- Clinically significant macular edema (CSMO), according to the Early Treatment Diabetic Retinopathy Study (ETDRS) guidelines: ${ }^{14}$

○ Retinal thickening within $500 \mu \mathrm{m}$ of the center of the fovea;

- Hard, yellow exudates within $500 \mu \mathrm{m}$ of the center of the fovea with adjacent retinal thickening;

- At least 1 disc area of retinal thickening, any part of which is within 1 disc diameter of the center of the fovea;

- Four or more previous macular laser treatments;

- No significant macular ischemia on fluorescein angiography;

- An attached vitreous (including vitreomacular traction), identified by biomicroscopy and B scan ultrasonography;

- No untreated retinal pathology (retinal breaks, significant degeneration, etc).

Exclusion criteria were:

- Epimacular membrane;

- Macular hole;

- Atrophic macular degeneration;

- Proliferative diabetic retinopathy;

- Inability to provide informed consent.

Pre-treatment investigations included visual acuity (ETDRS chart), biomicroscopy, fluorescein angiography, and optical coherence tomography (OCT) scanning (Stratus OCT, Zeiss Meditec, Jena, Germany); mydriasis of the treatment eye was accomplished with cyclopentolate $1 \%$ drops. Povidone iodine 5\% was applied around the affected eye and to the conjunctival sac. A volume of $0.3 \mathrm{~mL}$ of $100 \%$ perfluoropropane $\left(\mathrm{C}_{3} \mathrm{~F}_{8}\right)$ gas was then injected into the vitreous cavity at 3.5-4.0 $\mathrm{mm}$ posterior to the limbus via a 27 -gauge needle. The central retinal artery was visualized with an indirect ophthalmoscope and 20 dioptre lens. If it was observed to be occluded following gas injection, paracentesis was performed. The intraocular pressure was measured after 20 minutes.
Topical maxitrol and cyclopentolate 1\% drops (Alcon, Fort Worth, TX) were prescribed (and the appropriate hypotensive agent if there was an elevation in intraocular pressure), and the patient instructed to posture in a prone position for 40 minutes in each hour for 1 week.

Post-treatment evaluation was performed at 1 week, 1 month, 3 months, and 4-6 monthly thereafter. At each visit, visual acuity was measured and dilated biomicroscopy performed, together with OCT scanning. The central foveal thickness was used for analysis. Color fundus photography was also performed, but fluorescein angiography only if biomicroscopy and OCT findings provided insufficient information for an adequate evaluation. A minimum of 3 months was allowed to gauge the effect of the gas injection. A PVD was judged to have developed if there was a visible Weiss ring and/or posterior hyaloid face (PHF). B scan ultrasonography was performed in equivocal cases. If there was persistent CSMO by 3 months, consideration was given to administering additional therapy (laser, or intravitreal injection).

\section{Results}

Due to the strict inclusion and exclusion criteria for this study, only five eyes of five patients were recruited over a 2 -year period. All patients had type II diabetes, with a mean age of 69 (range 64-83) and mean review was 18 months (range 9-36). A PVD was induced in all eyes, with unequivocal vitreomacular separation being observed between 1 week and 1 month following injection in all cases. None of the patients treated had prior vitreomacular traction (although the efficacy of this method for this condition has been indicated in another publication by the authors. ${ }^{15}$ Signs of reduction in macular thickness and early resorption of exudates were observed by 1 month, with the beneficial trend continuing for 9-12 months following treatment. Median visual improvement and macular thickness was 11 ETDRS letters (range 4-21) and $157 \mu \mathrm{m}$ respectively (Table 1 and Figures 1-3). No eyes lost vision over the review period due to persistent or recurrent macular edema. Apart from a transient vitreous hemorrhage in one eye at 1 month (patient 2, possibly due to minor retinal vascular trauma during vitreous separation), there were no significant retinal treatment-related complications. In those eyes which were phakic, there was no observed progression of lenticular opacities. Although no patient required further macular laser therapy over the period of review, one patient (patient 5) developed an area of peripheral neovascularization 9 months following gas injection, and panretinal photocoagulation was performed. 

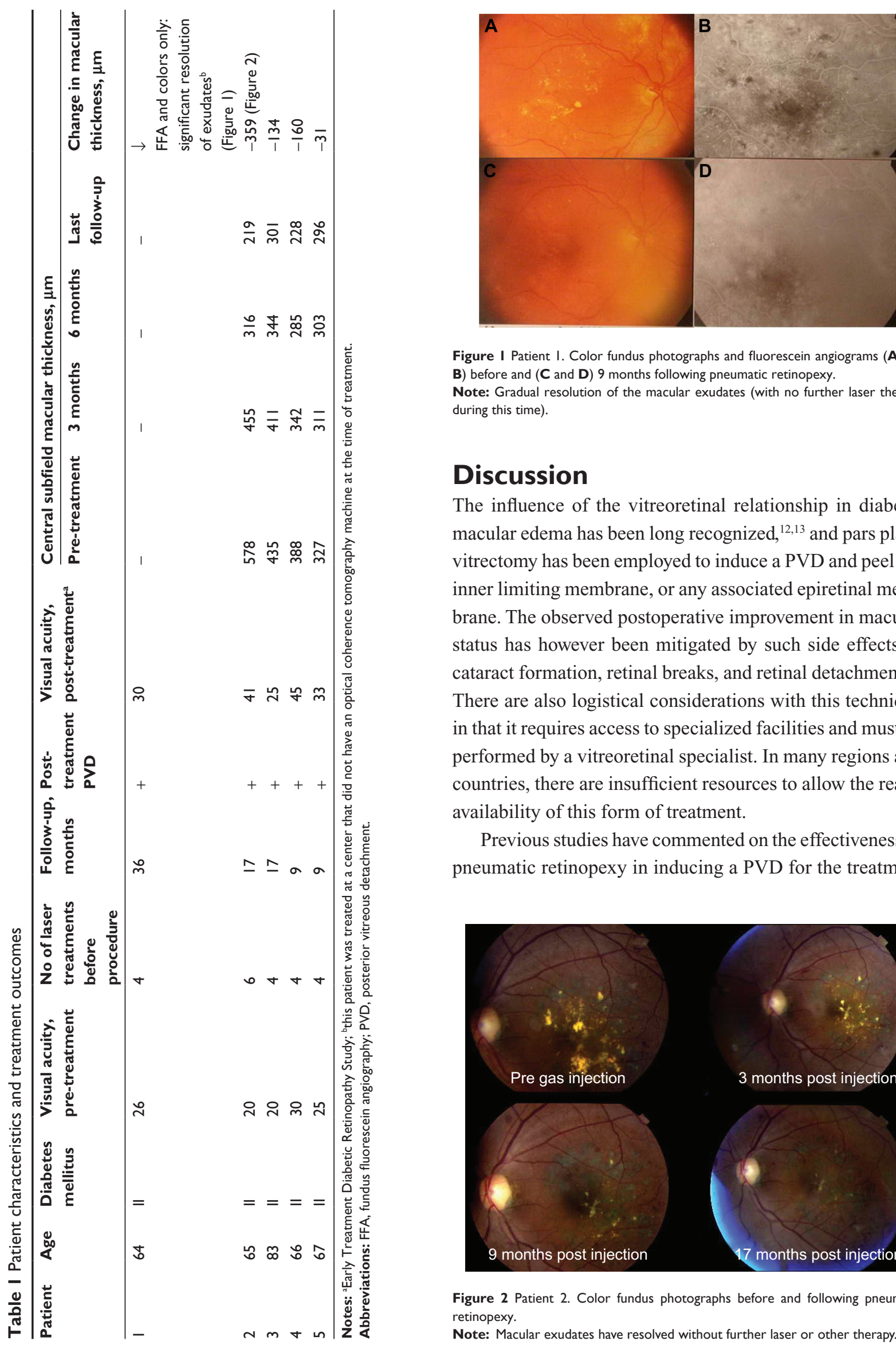

Figure I Patient I. Color fundus photographs and fluorescein angiograms (A and B) before and (C and D) 9 months following pneumatic retinopexy.

Note: Gradual resolution of the macular exudates (with no further laser therapy during this time)

\section{Discussion}

The influence of the vitreoretinal relationship in diabetic macular edema has been long recognized, ${ }^{12,13}$ and pars plana vitrectomy has been employed to induce a PVD and peel the inner limiting membrane, or any associated epiretinal membrane. The observed postoperative improvement in macular status has however been mitigated by such side effects as cataract formation, retinal breaks, and retinal detachment. ${ }^{8,9}$ There are also logistical considerations with this technique in that it requires access to specialized facilities and must be performed by a vitreoretinal specialist. In many regions and countries, there are insufficient resources to allow the ready availability of this form of treatment.

Previous studies have commented on the effectiveness of pneumatic retinopexy in inducing a PVD for the treatment

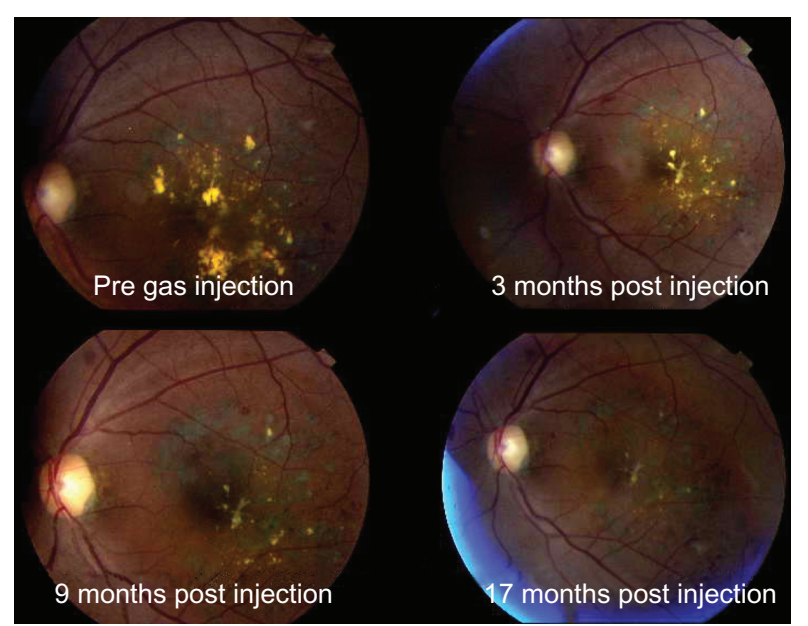

Figure 2 Patient 2. Color fundus photographs before and following pneumatic retinopexy.

Note: Macular exudates have resolved without further laser or other therapy. 
A
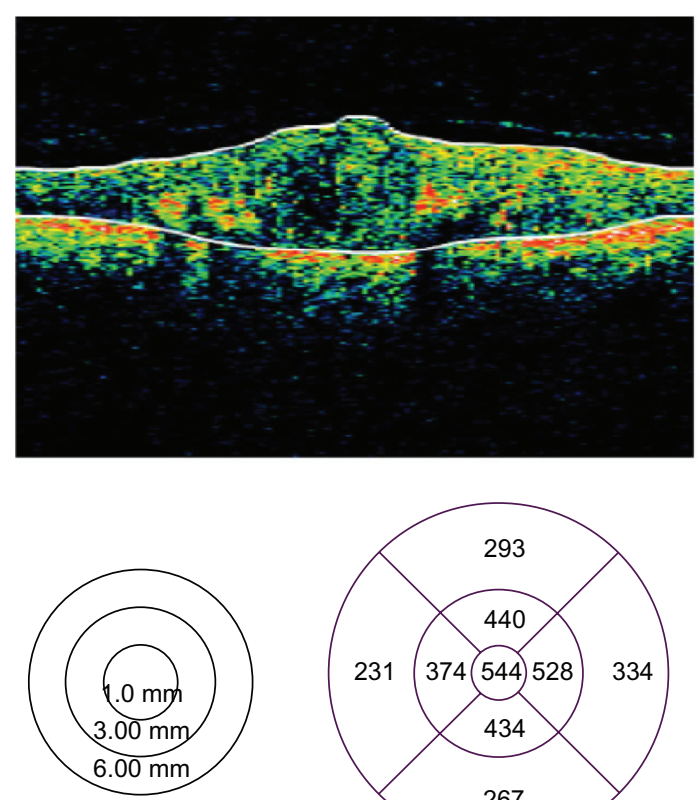

Map diameters
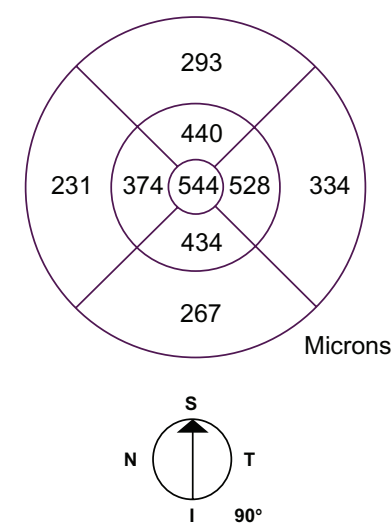

Fundus image

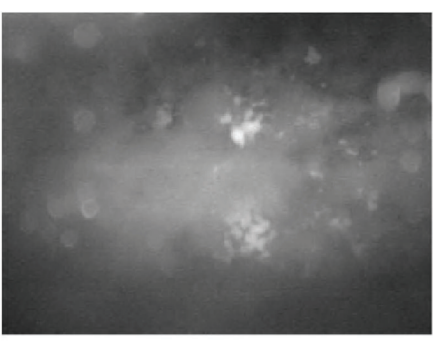

\begin{tabular}{|l|l|}
\hline Center & $578+/-23$ microns \\
\hline Total volume & $9.18 \mathrm{~mm}^{3}$ \\
\hline
\end{tabular}
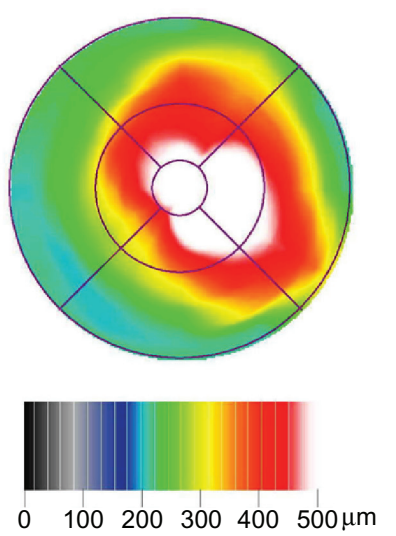

B

OCT image
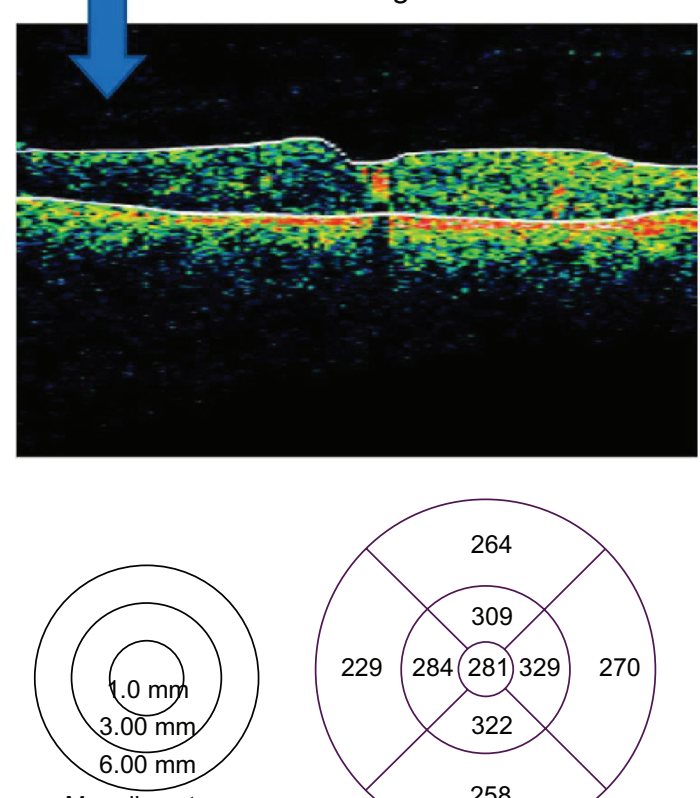

Map diameters

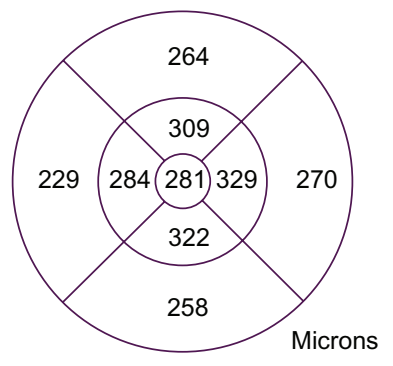

$N \overbrace{1}^{S} \int_{90^{\circ}}^{T}$
Fundus image

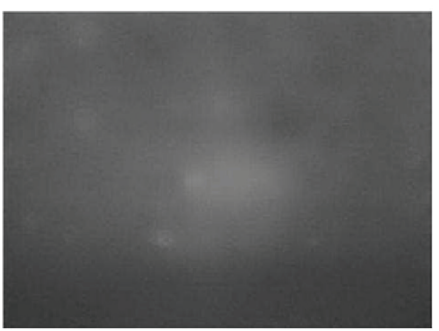

\begin{tabular}{|l|l|}
\hline Center & $219+/-17$ microns \\
\hline Total volume & $7.59 \mathrm{~mm}^{3}$ \\
\hline
\end{tabular}
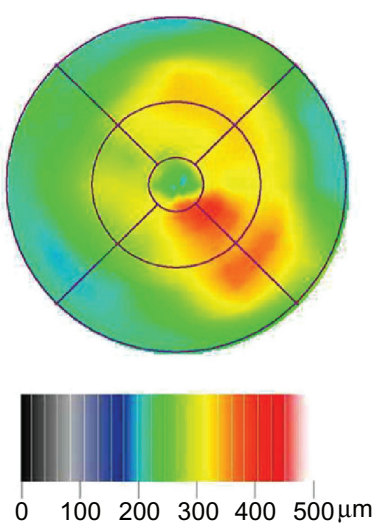

Figure 3 Patient 2. OCT images (A) prior to gas injection and (B) 17 months following pneumatic retinopexy. Reduction in macular thickness: 359 microns. Note: Separation of posterior hyaloid face (arrowed).

Abbreviation: OCT, optical coherence tomography. 
of macular holes and in cases of nonproliferative diabetic retinopathy, with consequent beneficial effects on the pathology. ${ }^{16,17}$ In the current study, the observed resolution of exudates and edema in these refractory cases was remarkable. Although the previous laser treatments might have had some beneficial effect, this may have been counteracted by persistent vitreoretinal traction, on which laser treatment alone would have had no significant influence. Apart from relief of traction, induction of a PVD may also confer a secondary beneficial effect in increasing retinal oxygenation derived from the fluid phase between the neuroretina and the PHF. An increase in oxygen tension within the inner retina could have a mitigating effect on macular edema by a number of mechanisms: reduced VEGF production causing decreased retinal vascular permeability; autoregulatory arteriolar vasoconstriction reducing hydrostatic pressure in capillaries and venules. There will be in turn decreased extravascular fluid flow (the Starling equation) and reduced edema formation. ${ }^{18}$

One notable feature of the current and of these previous studies utilizing gas injection is the low complication rate and in particular the absence of retinal tear or detachment formation, compared with pars planavitrectromy and indeed pneumatic retinopexy for established retinal detachment. ${ }^{19,20}$

In comparison with a vitrectomy, the relative safety of gas injection may relate to the gas having a gradual effect in separating the PHF from the retina, in the absence of preexisting peripheral retinal pathology (inducing a more "physiological" PVD).

Pneumatic retinopexy for an established retinal detachment confers compressive and tractional forces on vitreous and retina, which are already (at least partially) detached and as a consequence, secondary break formation is commonly observed, often at sites diametrically opposed to the original break location. A different situation is present when gas is injected into an eye where there is no PVD and no preexisting peripheral retinal pathology. Induction of a PVD in this instance is more analogous to the formation of a spontaneous PVD, which is typically associated with a risk of break formation of the order of $10 \%$ and a much lower risk of retinal detachment. ${ }^{21}$ In the current series, the high frequency of clinical review would in any case have identified any fresh retinal break formation, allowing its timely management (although to date this has not occurred).

The low numbers of eyes treated in this series reflects the cautious approach that was taken to a novel application of an established technique in eyes with advanced retinopathy. The promising results of this pilot series, together with the low complication rate now encourages the establishment of a randomized trial to test further the authors' hypothesis and arguably the incorporation of pneumatic retinopexy in combination therapy with laser photocoagulation and intravitreal steroid and anti-VEGF injection.

\section{Disclosure}

The authors report no conflicts of interest in this work.

\section{References}

1. National Diabetes Fact Sheet: General Information and National Estimates on Diabetes in the United States, 2005. Atlanta, GA: US Department of Health and Human Services, Centers for Disease Control and Prevention; 2010.

2. Ghafour IM, Allan D, Foulds WS. Common causes of blindness and visual handicap in the west of Scotland. Br J Ophthalmol. 1983;67: 209-213.

3. Photocoagulation treatment of proliferative diabetic retinopathy: the second report of diabetic retinopathy study findings. Ophthalmology. 1978;85:82-106.

4. Photocoagulation for diabetic macular edema. Early Treatment Diabetic Retinopathy Study report number 1. Early Treatment Diabetic Retinopathy Study Research Group. Arch Ophthalmol. 1985;103:1796-1806.

5. The effect of intensive treatment of diabetes on the development and progression of long-term complications in insulin-dependent diabetes mellitus. The Diabetes Control and Complications Trial Research Group. N Engl J Med. 1993;329:977-986.

6. Ryder B. Screening for diabetic retinopathy. BMJ. 1995;311:207-208.

7. Vora SR, Hagedorn CL, Khan N, Aslan M, Concato JP, Adelman RA. Is repeat macular laser photocoagulation effective in the management of diabetic macular edema? Invest Ophthalmol Vis Sci. 2005;46:396.

8. Grigorian R, Bhagat N, Lanzetta P, Tutela A, Zarbin M. Pars plana vitrectomy for refractory diabetic macular edema. Semin Ophthalmol. 2003;18:116-120.

9. van EG, Guyot-Argenton C, Guiberteau B, Hany I, Lacotte JL. Macular edema caused by contraction of the posterior hyaloid in diabetic retinopathy. Surgical treatment of a series of 22 cases. J Fr Ophtalmol. 1993;16:602-610.

10. Arevalo JF, Fromow-Guerra J, Quiroz-Mercado H, et al. Primary intravitreal bevacizumab (Avastin) for diabetic macular edema: results from the Pan-American Collaborative Retina Study Group at 6-month follow-up. Ophthalmology. 2007;114:743-750.

11. Thompson JT. Cataract formation and other complications of intravitreal triamcinolone for macular edema. Am J Ophthalmol. 2006;141:629-637.

12. Nasrallah FP, Jalkh AE, Van CF, et al. The role of the vitreous in diabetic macular edema. Ophthalmology. 1988;95:1335-1339.

13. Tachi N, Ogino N. Vitrectomy for diffuse macular edema in cases of diabetic retinopathy. Am J Ophthalmol. 1996;122:258-260.

14. Grading diabetic retinopathy from stereoscopic color fundus photographs - an extension of the modified Airlie House classification. ETDRS report number 10. Early Treatment Diabetic Retinopathy Study Research Group. Ophthalmology. 1991;98:786-806.

15. Gupta B, McHugh D. Pneumatic retinopexy for the management of impending macular hole: an optical coherence tomography study. Int Ophthalmol. 2011;31:23-24.

16. Chan CK, Wessels IF, Friedrichsen EJ. Treatment of idiopathic macular holes by induced posterior vitreous detachment. Ophthalmology. 1995;102:757-767.

17. Mori K, Saito S, Gehlbach PL, Yoneya S. Treatment of stage 2 macular hole by intravitreous injection of expansile gas and induction of posterior vitreous detachment. Ophthalmology. 2007;114:127-133. 
18. Hendrikse F, Yeo KT. Role of the vitreous body in diabetic retinopathy. Klin Monbl Augenheilkd. 1993;203:319-323.

19. Chan CK, Lin SG, Nuthi AS, Salib DM. Pneumatic retinopexy for the repair of retinal detachments: a comprehensive review (1986-2007). Surv Ophthalmol. 2008;53:443-478.
20. Chen JC, Robertson JE, Coonan P, et al. Results and complications of pneumatic retinopexy. Ophthalmology. 1988;95:601-606.

21. Tanner V, Harle D, Tan J, Foote B, Williamson TH, Chignell AH. Acute posterior vitreous detachment: the predictive value of vitreous pigment and symptomatology. Br J Ophthalmol. 2000;84:1264-1268.

\section{Publish your work in this journal}

Clinical Ophthalmology is an international, peer-reviewed journal covering all subspecialties within ophthalmology. Key topics include: Optometry; Visual science; Pharmacology and drug therapy in eye diseases; Basic Sciences; Primary and Secondary eye care; Patient Safety and Quality of Care Improvements. This journal is indexed on

\section{Dovepress}

PubMed Central and CAS, and is the official journal of The Society of Clinical Ophthalmology (SCO). The manuscript management system is completely online and includes a very quick and fair peer-review system, which is all easy to use. Visit http://www.dovepress.com/ testimonials.php to read real quotes from published authors. 